\title{
日十二月二年三十四治 明
}

り、《容 が若旦長生し、光附

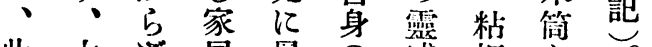
此古ざ屋兒の威板と 。 神來るの簬他留竖は本 琹出際修守に存老、文

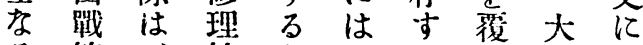
る 等、等と蓝小訅 木の 必 の \& 别し立 せ

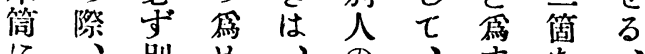
亿、别め、の 全硶に、忽開最、方總

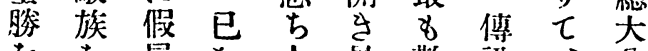

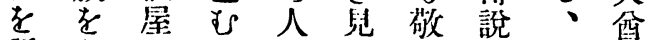
淅殺を索をる虔に共長

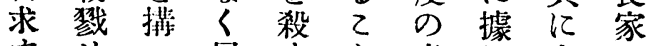
寸せへ屋すと意れ木に

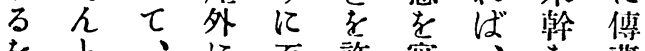

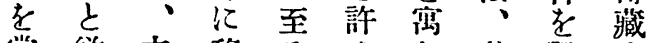

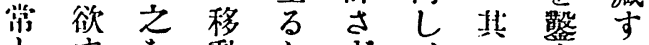
之す卷動とず、の 空る する深世信、總中去神

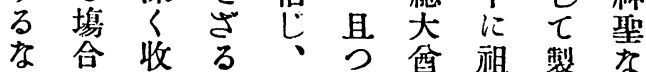

し 爾族 の 其 後を中の 叙 殺に家

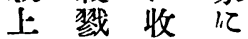
の しさ傅 㵶矿或藏 式 預 或 す に澦はる 變を它神 形䛜或く毠 せ取、劣 るし往る な來古术 b 万此 简 支際俩 恐行 は 勝

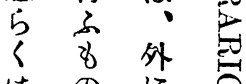
はの往 是な纱军 な $\begin{array}{llll}3 & L & L & \Xi \\ \text { に } & \text { \&े } & \tau & \Xi\end{array}$ 近、買

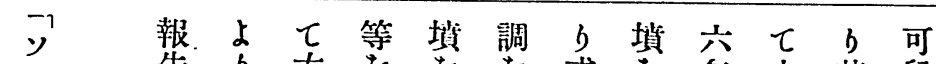
デ 告 b克を索或を年小其兒 ウし 石填發發抬生發一字丙郡

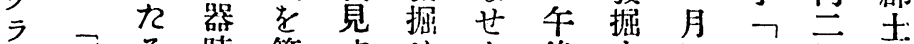

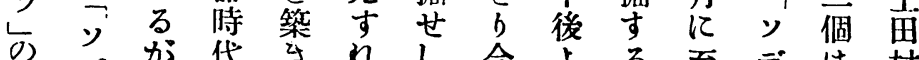

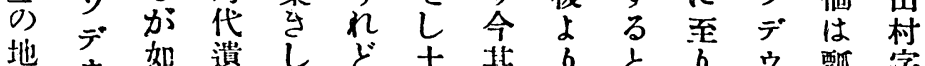
地 然亏し物者名中取士聞三今形渡 は「、のに以む調画尘個し古に

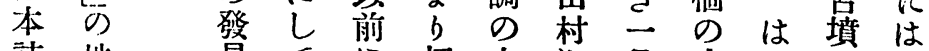
誌地自 $\tau$ 打大打古明浽山

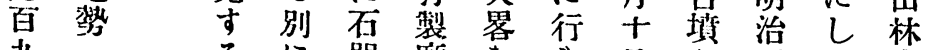

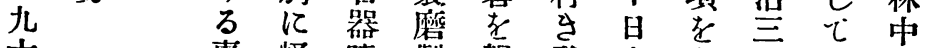
$+$ 九

號

に

訅

ᄂ

$\frac{2}{3}$

安

如

木

事怪時製報發十發干淇に

は和代石ず䅐要掘五他大

已に遗境れ物百世年少 に足物及ば度十るよ皆凡

本点存貝

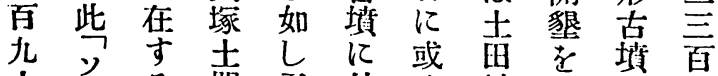

†デる器文付は村な极の

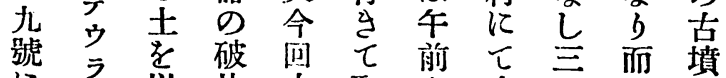


號七十八百二第誌雜會學類人京東

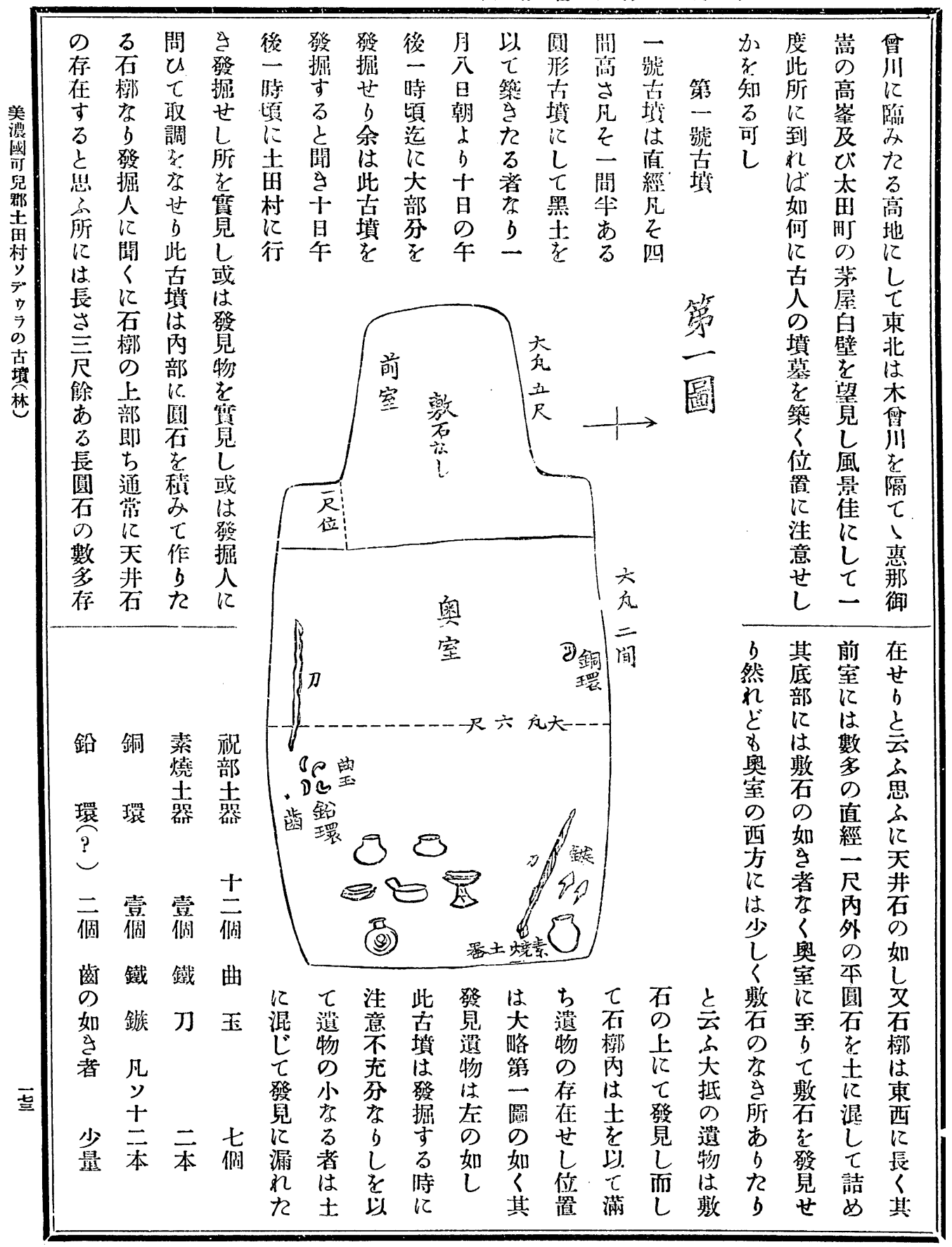


日十二月二年三十四治明

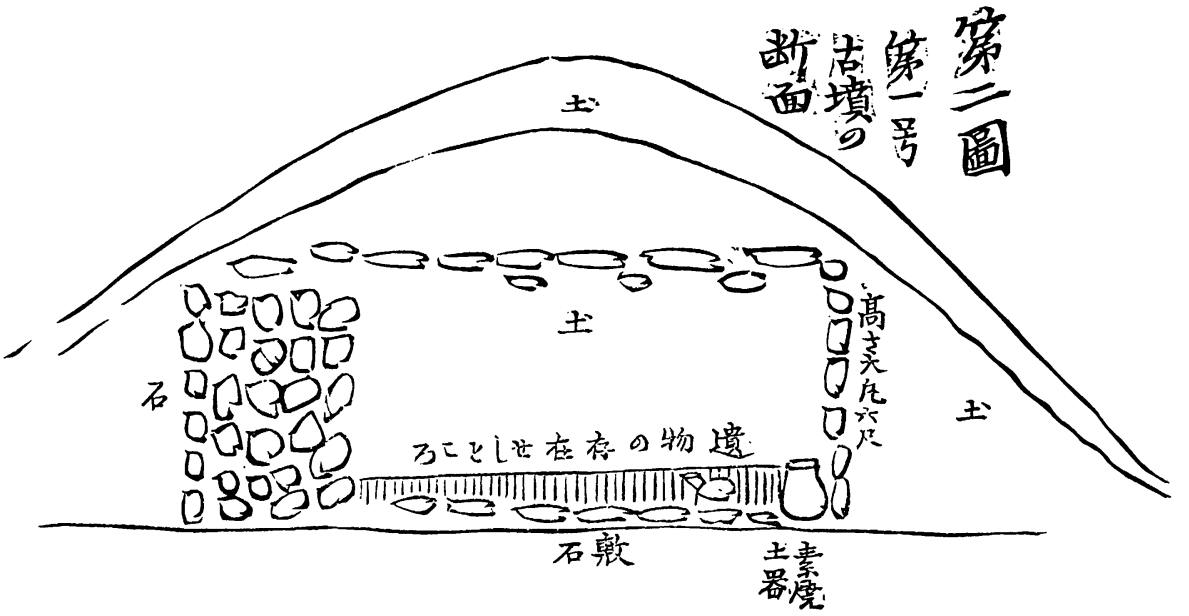

如のあ數 發 重 數 ケ土に士あ等大見はとる

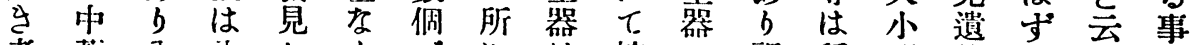

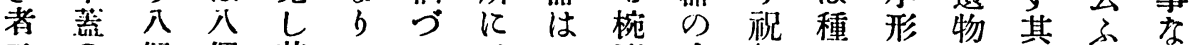

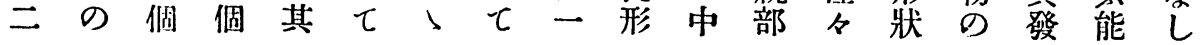

㖪 所刀と色環 別し曲見は而素れ如色素個

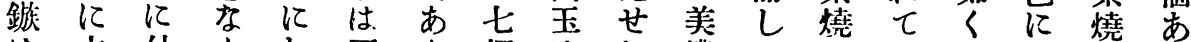

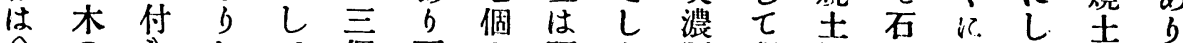

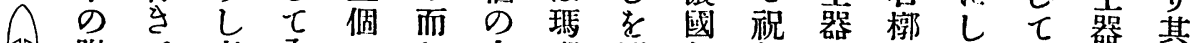

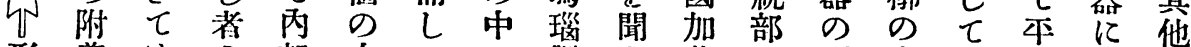
形着はの 部中て 一製少茂士石東彌底は可

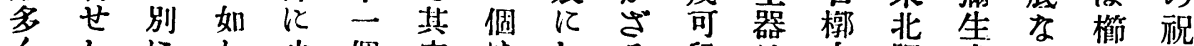
くしにし少個穴はしるる兒は中隅式 b部

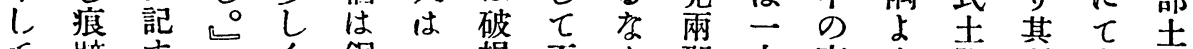

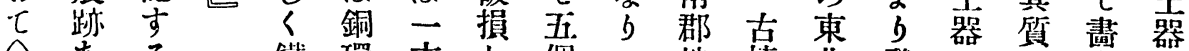

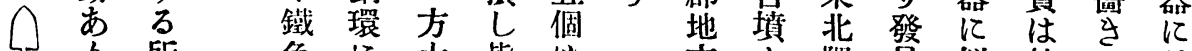
の 色所 大皆生方少隅見似軟た付

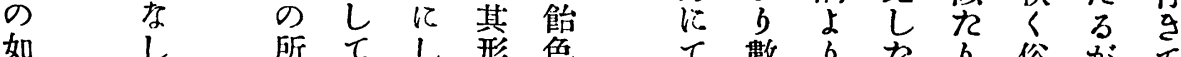

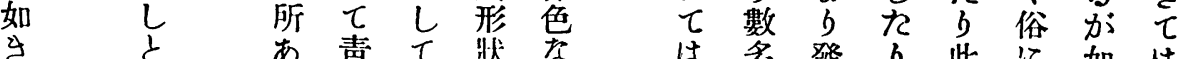
者 あ 毒 は 鋁鉛色 は 鉛を方關ど 古兒せ 濃 器ふ數に

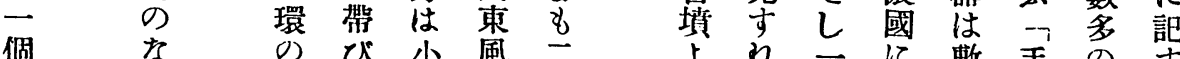

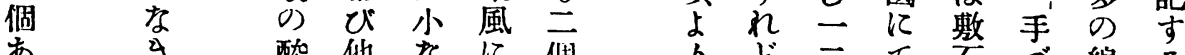

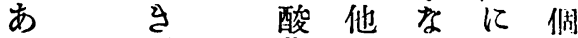
る 刀 化の b传 の は し二白 み中值 中色 な先白は少に b 色白 の 近

b ど 二 て 石 ゔ線る 
號七十几百二第誌雜會學類人京東

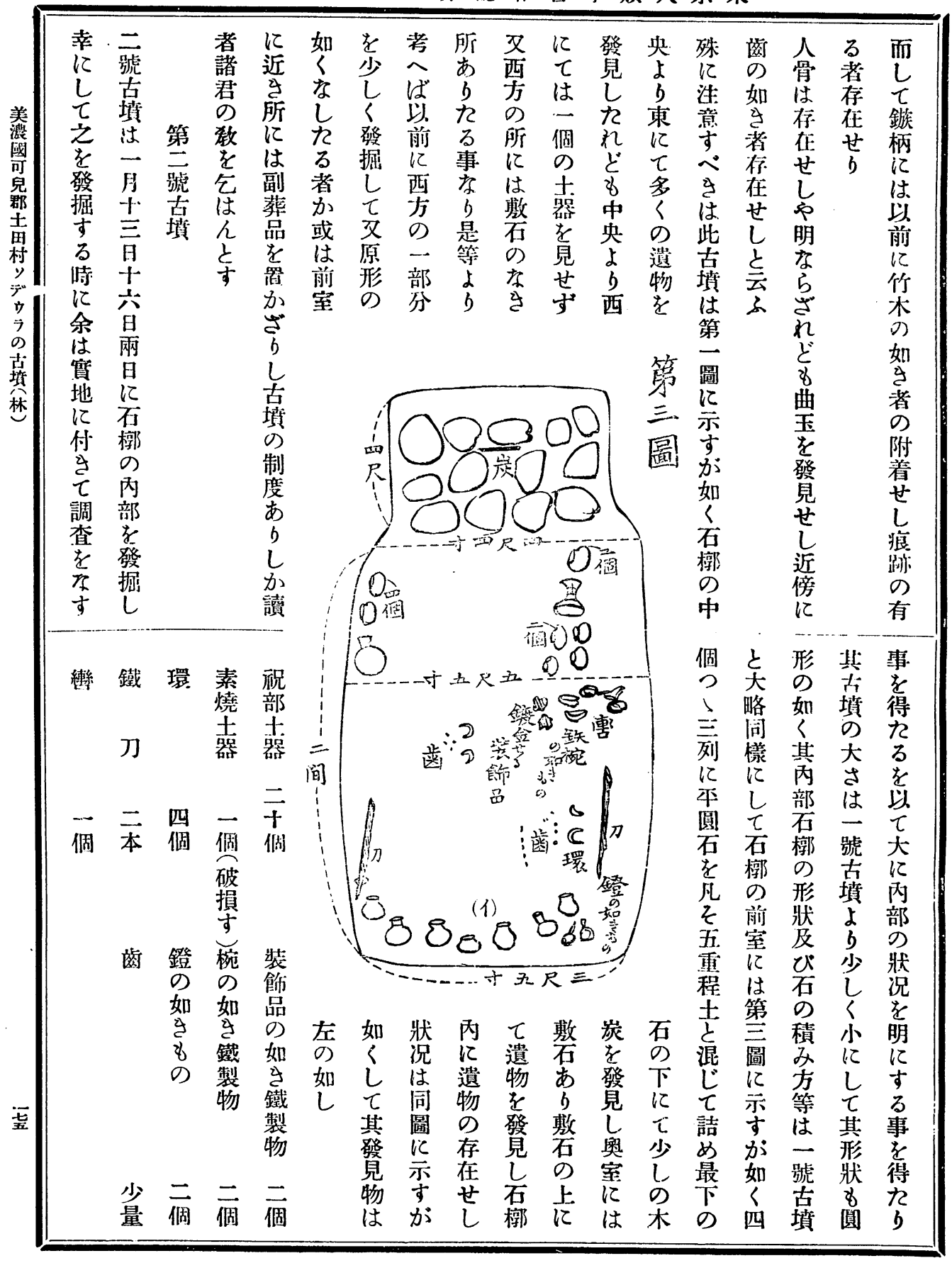




\section{日十二月三年三十四治明}

花 形 (面断9境古号二采)圆血第

の に

鐵 示

製 す

品者

には

ᄂ 此

七 菜

表 燒

面 声

舁器

尔存
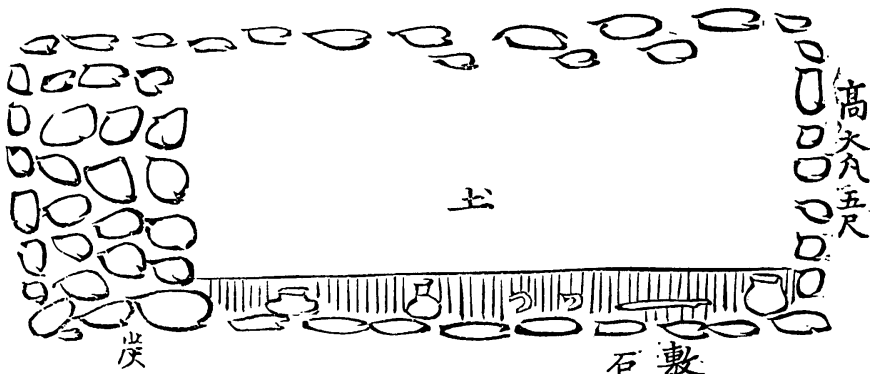

3

吾

IIIIILC=

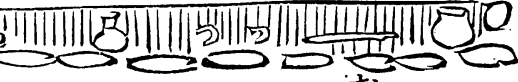

Q

所 在

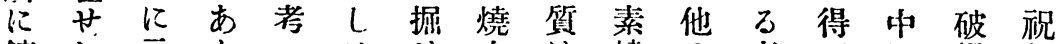

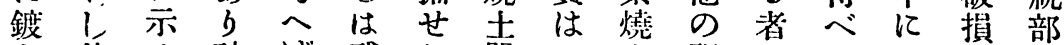

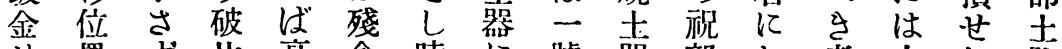

せ置 寸片高念時に號器部し.者大しし器

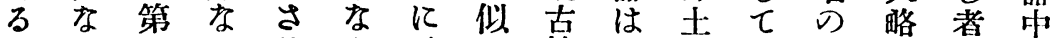

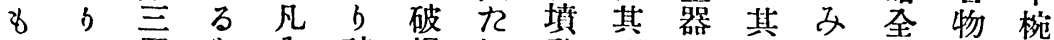

の四蓝飞破損れ發形七十形多形

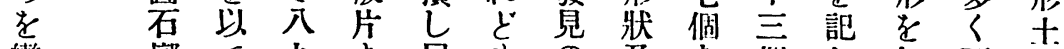

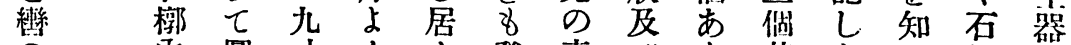

其

ば發

左見

の 物

如 $の$

及

ひ

形

狀

等

は

種

名

な

b

今

其

t

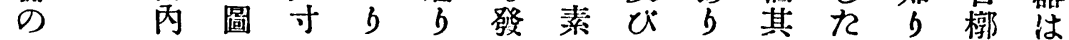

略

辇

明

す

8 然の 發を 尺齿金なる 環本䤼す ど見 又近

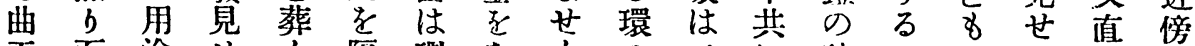

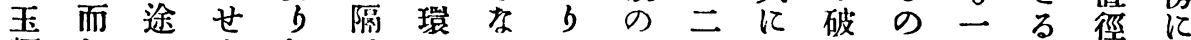
類しし はて 付此者】發他石個づ尺の是は以發 發此さの な 發見の 槨はすに如亦底前六見

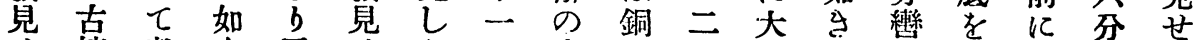

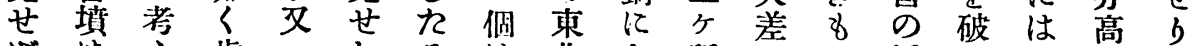

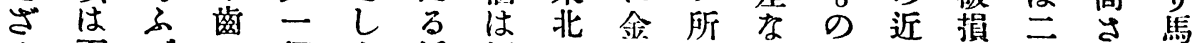
b石 $の$ 個よ近銅に鍍よしし傍せ 個七具 し 槨 2 近 $の b$ 傍

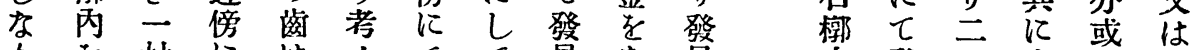
りを材にはふてて見な筧發個底は 电

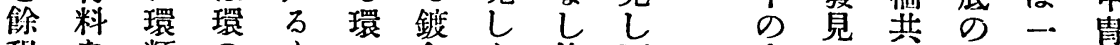
程な 類の 8 の 金 た 他石

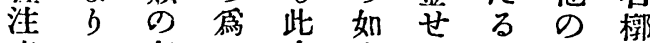
意存め古くし環 一 の し 在に㸉三者の個中

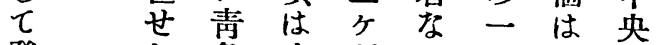
發し色少所る倜銅に 掘はにくななは市 L 金 染と b 明銅 銀 發 た 銀文子凡なに鍍見

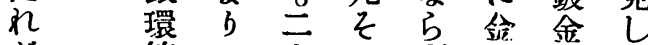

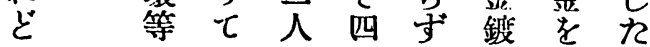

東世们存 寸類 北 b 酸 在の の 部化 世椀装 に腐し 形飾 七 蝕者 鐵 品 發しな製な 見它品ら し 原允嵒 刀 形亡 二

は觉個

二有 北 